the lower teeth interlock in an exact manner with the upper. The hold or grip of a wolf fish must therefore be of a tenacious kind. Behind these incisor teeth, botb above and below, are seen a few small teeth, destined by the ordinary laws of dental succession in the fish-group to replace the incisors in case of injury or loss. These front teeth are firmly anchylosed to the bones on which they are borne.

More interesting are the palatal teeth, and the corresponding teeth of the lower jaw. To these latter, the name of "molars" or "grinders" is frequently applied. Close to the front of the upper jaw we find a series of three tooth-masses, one central and two lateral, arranged in diverging fashion. The central and largest mass resembles the tuberculate molar of a bear in form, and is composed of four firmly united segments, each segment in turn consisting of two pieces. The lateral teeth of the palate, similarly consist of a double series of firmly united segments, but in each of these lateral pieces the outer row of pieces is composed of sharp-pointed segments, resembling miniature incisors. The accompanying diagram will afford an idea of these curious palatal arrangements :
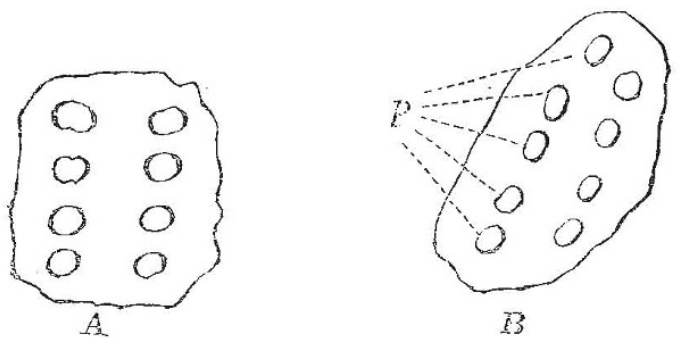

13

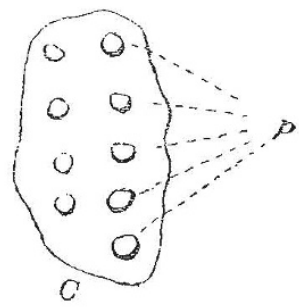

$\mathrm{A}$ is the central piece; $\mathrm{B}$ and $\mathrm{C}$ are the lateral pieces, the outer teeth of which $(\phi p)$ consist of pointed and incisor-like pieces. It follows from this description that the sea wolf possesses in its mouth an apparatus not merely adapted for tearing its food but for exercising a triturating and bruising action as well.

No less characteristic are the dental arrangements of the lower jaw. In the front of this jaw are four incisor teeth, each fully three-quarters of an inch in length; whilst two smaller incisors exist as already mentioned, one at each side of the larger series. Behind these incisors are the rudiments of succeeding teetb, and these rudimentary teeth gradually merge into the main dental arrangement of the lower jaw, which consists of a prominent row of blunt teeth anchylosed to form a common mass, and partially forming a double row on each side of the jaw. Section of the jaw shows that the teeth are imbedded in a common groove, and that complete and thorough ossification of the various dental pieces renders the whole apparatus compact and solid. The arrangement seen in the mouth of the wolf fish suggests the idea of the high specialisation of this type of fish, as indicated by the development of the dental apparatus. In none of the near neighbours of this fish have we at all a near approach to the perfection of teeth thus exhibited; and in respect of its complexity and differentiation of type, we may well be inclined to lend some countenance to the idea of the independent origin in widely removed fishes of structures seen in still greater perfection in such widely-removed fishes as the Elasmo. branchiate Skates, Rays, and Cestracion.

The stomach of the specimen I dissected was greatly distended, and contained fully four ounces of digestive débris, consisting chiefly of disintegrated Ophiuroids, spider-crabs, broken shells, shrimps and prawns, along with sand and small gravel. The pyloric aperture was firmly contracted and the collection of matter in the stomach clearly pointed to some obstruction of the digestive canal as the cause of death. It was also instructive to find that close to the vent the rectum was largely distended with broken pieces of shells and fine gravel. These matters, along with those in the stomach, had evidently been intussuscepted before the arrival of the fish in the aquarium and probably caused death by the irritation consequent on their non-removal by digestion.

ANDREW WILSON

\section{THE ETNA OBSERVATORY}

$\mathrm{T} \mathrm{T}$ will be within the recollection of some of our readers that in September, 1876 , Prof. Tacchini, of Palermo, communicated to the Accademia Gioenia of Catania a letter, "Sulla Convenienza ed utilita di erigere sull' Etna una Stazione astronomico-meteorologica " (vide NATURE, vol. xv. p. 262). This letter was published in the Atti of the Academy, and afterwards appeared in the form of a quarto pamphlet with ground-plan and elevation of the proposed building. The project was at once taken into consideration both by the Italian Government and by the Municipality of Catania; plans were prepared, money was voted, and it was confidently believed that the ob. servatory would be commenced in July, 1878. Owing, however, to certain delays, this was found to be impracticable, and the commencement was postponed till June, 1879. There is every reason to believe that the building will be erected and the instruments in working order by the end of this year. The cost will be borne by the Government, the Municipality of Catania, and the Province of Catania. Merz, of Munich, has offered to construct a 12 -inch lens for the great-refractor, at the price of a Io-inch lens, and the enterprise has received encou. ragement and support from variots sources both at home and abroad.

The observatory will be erected at the Casa degl' Inglesi, 9,652 feet above the level of the sea. At the present time the Casa is an oblong building constructed of blocks of lava, and containing three rooms (vide the accompanying plan). It was built by the English when they occupied Sicily in I8r , and has since been used by those who ascend the mountain as sleeping quarters. A few years ago it had fallen into decay owing to the accumulation of snow in winter and to other causes, but it was put into complete repair in 1862 on the occasion of the visit of the present King of Italy. The observatory will be the property of the University of Catania, and will indeed be a kind of offshoot of the Bellini Observatory of Catania. It is to be devoted not only to astronomical and spectroscopic observations, but it will also be furnished with a complete set of meteorological and seismological instruments. Between the Etna Observatory and Catania three or four meteorological stations will be established at different elevations, as at Nicolosi, and the Casa del Bosco, and observations will be made at the same hour daily at each of these stations, at Catania, and at the Etna Observatory.

The Merz lens of 12 inches diameter, has a focal distance of $5 \frac{1}{2}$ metres. The telescope and clock-work movement are in course of construction by Signor Carignata, the mechanician of the Padua Observatory, who constructed the instruments which were employed by the Italian astronomers who went to India to observe the transit of Venus in 1874 . The observatory will only be inhabited during the months of June, July, August, and September, and the large lens will then be transported 
to Catania, and fitted to a duplicate mounting in the Bellini Observatory. But a number of self-recording instruments will remain in the observatory, and thus results will be registered during the winter months.

Prof. Tacchini, to whom the whole undertaking owes its existence, specially desires that it should be an International Observatory. With this object in view, the large telescope will be fitted with a second tube, the length and aperture of which can be altered at will, so that astronomers from any part of the world can bring with them their objectives and eye-pieces, and can fit them to the telescope of the observatory. Special arrangements will be made for photographing the sun and moon, and for spectroscopic observations.

The observatory will contain the large telescope covered by the usual dome in the centre; on each side there will be rooms for the other instruments, and below, sleeping quarters, a dining-room, and kitchen for the use of travellers. The following plan, for which, together with many of the above facts, we are indebted to Prof. Tacchini, will show the general arrangement of the observatory.

In his report on the subject Prof. Tacchini commences by pointing out that since the year 1868 the study of the physical constitution of the sun has made very rapid progress. In these studies the spectroscope has played a very important part. But the spectroscopic observations are often hindered, and their exactitude is disturbed by atmospheric causes, and these disturbances are mainly due to the lower layers of the atmosphere. Hence an observatory at a considerable elevation would greatly facilitate such observations. The isolated Mount Etna affords an admirable locality for such an observatory. The blueness of the sky is intense, the stars shine vith an extraordinary brightness, Venus casts shadows, spectroscopic lines which cannot be seen at the Palermo Observatory are perfectly distinct when viewed from an elevation of Io,000 feet. "Ora il mio desiderio," says Tacchini, "sarebbe quello di andare sull" Etna per verificare la tanto decantata purezza del cielo e il suo colore speciale, oșservare l'aureola del sole, studiarne lo spettro se sarà possibile e fare anche qualche tentativo di fotografia. ..." He then mentions some of the observations made by Young with a 9 -inch refractor at an elevation of 2,800 metres, and describes his own observations made on Etna with a Dollond refractor of $99 \mathrm{~mm}$. aperture,

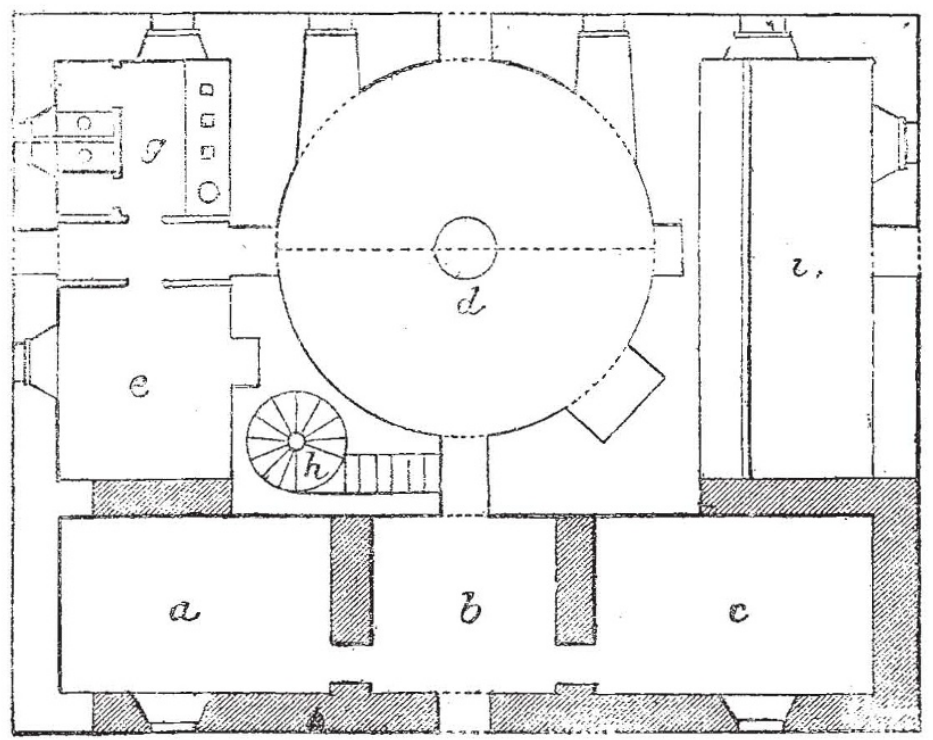

$a, b, c$, the three rooms of the already existing Casa Inglesi; $d$, circular chamber, 8 meires in diameter, with a massive pillar in the centre, upon which the great refractor will be placed; $e$, a room for guides who accompany those who ascend the mountain; $z$, kitchen and offices; $i$, stable for mules; $h$, staircase. On the upper flor, $a, b, c$, will be bed-rooms $i, g, i$, instrument-roms; and $d$, the circular chamber fur the refractor, extending through both floors, and surmounted by a movable dome of iron.

and a spectroscope of great dispersive power constructed by Tauber. "La cromosfera era magnifica e dettagliata abbastanza tenendo conto della piccolezza del magnesio e dello I474, ciò che non vidi a Palermo collo stesso cannocchiale." Then having made the suggestions which are in part carried out, and which have entirely been adopted, he concludes by a fervid peroration which we heartily endorse :- "Io ritornerò dunque all' Etna, lo spero, e in migliore stagione, e sin d'ora mi figuro coll' immaginazione, la vista della nuova specola, che mi ricorderà l'epoca fortunata e la circonstanza solenne, che qui mi tiene ora unito a voi, e il nome del grande Bellini, che prima ancora di dare alle scene il suo capo lavoro, la Norma, volle in omaggio alla scienza degli astri, suonare all' osservatorio di Palermo la celeste melodia della preghiera alla casta Diva."

While we feel perfectly convinced that important results will accrue to more than one science from the establishment of the new observatory, we must not shut our eyes to the fact that many difficulties will have to be encountered. The observatory on Vesuvius stands upon a projecting spur of rock, and lava-streams of any ordi- nary magnitude breaking out on this side of the cone would divide, and leave the observatory as on a rocky island. But the Etna Observatory will stand near the upper termination of the Piano del Lago, the plain out of which the great cone of Etna rises. A great eruption, leading to the breaking down of the cone and flow of lava in this direction, could not fail to overwhelm the Observatory. Fortunately the lava usually finds vent by a bocca del fuoco on the sides of the mountain below the great cone. The building must be of very great strength; it will be subject to violent shocks of earthquake, to fierce storms of wind, and to the accumulation of great masses of snow upon its dome and roof. Those who have read the history of the mountain know with what tremendous power it scatters its terrors abroad; how hours of loud bellowings and detonations are followed by days of violent earthquake, and weeks during which many square miles of country are inundated by millions of cubic yards of molten lava. That the new Observatory may flourish, unassailed by the fearful forces of the imprisoned Cyclops, will be the wish of all our readers.

G. F. RODWELL 